\title{
Hysteroscopy to identify retained placental tissue and excision in secondary post-partum haemorrhage
}

\author{
Pratibha Devabhaktuni*, Padmaja Allani
}

\begin{abstract}
Department of Obstetrics and Gynecology, Modern Government Maternity Hospital, Osmania Medical College, Hyderabad, Telangana, India
\end{abstract}

Received: 27 February 2020

Accepted: 13 April 2020

\section{*Correspondence:}

Dr. Pratibha Devabhaktuni,

E-mail:dpdnk@yahoo.com

Copyright: (c) the author(s), publisher and licensee Medip Academy. This is an open-access article distributed under the terms of the Creative Commons Attribution Non-Commercial License, which permits unrestricted non-commercial use, distribution, and reproduction in any medium, provided the original work is properly cited.

\begin{abstract}
Background: Most cases of secondary postpartum haemorrhage (PPH) are due to retained placental products (RPP). This study had a crop of five cases of secondary PPH, referral cases, during a period of six months during 2006. Four cases were following a caesarean delivery and in one, sub mucous and intra mural, uterine fibroids, caused retained placental tissue by distortion of the uterine cavity. Objectives of this study were to evaluate the feasibility of hysteroscopy to identify the retained placental products in cases of secondary postpartum haemorrhage. Verification of complete removal of RPP by reinsertion of hysteroscope, after removal of RPP by using a sponge holder, or curette.

Methods: Trans vaginal ultrasonography (TVS) identified echogenic retained products of conception in all cases. Surgical profile investigations were done as per protocol. Transfusion of blood products was needed in some. Bettocchi $5 \mathrm{~mm}$ continuous flow hysteroscope (Karl Storz) was used. Storz endomat hysteroflator was used for irrigation and aspiration.

Results: Hysteroscopic guided excision of the placental tissue was one-time treatment in four of study cases, and one needed a second hysteroscopic excision. Secondary PPH occurred at varying periods after the caesarean delivery, one week in one, two weeks in one case, three weeks in two cases and one woman was admitted with retained placenta, primary PPH continuing to secondary PPH. Hysteroscopy done during the puerperal period, in cases of secondary $\mathrm{PPH}$, had certain challenges to cope with.

Conclusions: Hysteroscopic guided excision of the retained placental tissue was successful in all the five cases with secondary postpartum haemorrhage. Hysteroscopy is an excellent procedure in cases of secondary PPH. We request guidelines committees to consider including hysteroscopic guided removal of retained placental products, in the algorithm of management of secondary PPH.
\end{abstract}

Keywords: Hysteroscopy, Postpartum haemorrhage, Retained placental products

\section{INTRODUCTION}

Secondary postpartum haemorrhage (PPH) is defined as excessive vaginal bleeding from 24 hours after delivery, to up to six weeks postpartum. Most cases of delayed $\mathrm{PPH}$ are due to retained products of conception, infection, subinvolution of the placental implantation site and choriocarcinoma. Other causes include, lower genital tract lacerations/hematoma, surgical injury, dehiscence of
Caesarean section scar, fibroids, arterio venous malformation and coagulopathies. ${ }^{1,2}$ It is not an uncommon complication following a vaginal delivery with a reported incidence of 0.5 to $1.3 \%$, but is associated with serious maternal morbidity and mortality. ${ }^{3}$ Overall, the reported incidence of secondary PPH in the developed world varies from $0.47 \%$ to $1.44 \% .^{3,4}$ Retained placenta is a serious cause of postpartum hemorrhage. Compounding this problem is the rare finding of a retained placenta 
accreta. Different authors have presented management options for retained placenta accreta that include methotrexate, uterine artery embolization, dilation and curettage, hysteroscopic loop resection, and hysterectomy.

Hoveyda $\mathrm{F}$ et al, in an analysis of 132 consecutive cases of secondary postpartum haemorrhage over a three-year period, observed that a history of primary postpartum haemorrhage and the manual removal of the placenta were the risk factors identified. ${ }^{3}$

\section{Causes of secondary PPH can be classified as}

- Subinvolution of the uterus due to - retained placental tissue and/or endometritis

- Fibroid uterus

- Lower genital tract lacerations/hematoma

- Placental abnormality - placenta accreta, increta and percreta

- Choriocarcinoma

- Coagulopathies, bleeding disorders, use of anticoagulants

- Dehiscence of cesarean section scar

- Vascular abnormality - arteriovenous malformation

- Surgical injury - cervical tears extending to lower uterine segment, leading to broad ligament haematoma and intraperitoneal bleeding, uterine perforation secondary to manual removal of the placenta.

Other rare causes of secondary PPH are, vessel subinvolution (VSI) of the placental implantation site, uterine artery pseudoaneurysm (UAP). ${ }^{5,6}$ Secondary PPH due to dehiscence of caesarean section scar have been reported by many. ${ }^{7,8}$

In the management of secondary PPH, the various surgical procedures adopted were, uterine evacuation, uterine tamponade balloon, uterine compression sutures, hysterectomy, pelvic arterial ligation, radiological intervention - selective arterial embolization.

To be successful in the management of secondary PPH, it becomes mandatory to identify the causative factor so that study can choose the specific operation based on the aetiology, meant for uterine atony, for retained placental products, for adherent placenta, uterine artery peudo aneurysm and other specific causes.

This study presents five cases of secondary PPH admitted to study Institute, during 2006. Some of them required multiple transfusions of blood products. Ultrasonography identified echogenic retained products of conception; study performed hysteroscopic guided excision. Hysteroscopic guided excision and removal of retained placental tissue is a novel procedure, very successful in selected cases of secondary PPH. The retained placental tissue is identified by ultrasonography.
Aim

- To share study experience of managing secondary postpartum haemorrhage following caesarean section done in private health facilities and referred to tertiary Institute.

- To disseminate study conclusion that hysteroscopy provides identification of the causative factor and proper management.

\section{METHODS}

Trans vaginal ultrasonography (TVS), performed on the day of admission, identified echogenic retained products of conception in all cases. Surgical profile investigations were done as per protocol. Transfusion of blood products was needed in some, preoperatively. Bettocchi $5 \mathrm{~mm}$ continuous flow hysteroscope (Karl Storz) was used. Storz endomat hysteroflator was used for irrigation and aspiration. Though an operating channel through which instruments could be passed was available, study opted to remove the RPP with a sponge holder as we can grasp larger amount of tissue and remove it in one go, it would cut short the procedure time. Curettage was also needed in some. All the procedures were performed under general anesthesia. Tissue was sent for histopathology in all cases. Patients were under follow up for a couple of months.

\section{RESULTS}

\section{Material and management of secondary $\mathrm{PPH}$ by hysteroscopy}

Case 1

A woman with continuous bleeding per vaginum was referred to study Institute of obstetrics and Gynaecology, Government Maternity Hospital, Ameen Bagh, Osmania Medical College, (now referred to as MGMH, Petlaburz, because of relocation) on $8^{\text {th }}$ May 2006.

She had a caesarean section done on $28^{\text {th }}$ February 2006, in a private health facility, para 2 , live children two. She started having continuous vaginal bleeding 21 days after the caesarean delivery, was managed conservatively with antibiotics, haematinics and antifibrinolytics, one-unit blood was transfused. As the bleeding continued unabated, she was sent to the Institute on $8^{\text {th }}$ May 2006, for further care. At admission her general condition was stable, though pallor was noted, per abdomen uterus was palpable, 14 weeks gestation size, (68 days after $\mathrm{C}$. section), and no active vaginal bleeding.

A trans vaginal ultrasound scan performed on the day of admission, on 8th May 2006 reported an irregular hyperechoic lesion $28 \times 18 \mathrm{~mm}$ in mid uterine cavity? retained placental tissue. A beta HCG test was done to rule out gestational trophoblastic disease, (GTD) or a new conception, reported as $-4.5 \mathrm{miu} / \mathrm{ml}$. Other preoperative 
surgical profile investigations were done as per protocol. Hysteroscopy was performed on $12^{\text {th }}$ May 2006, the findings were, endocervical canal normal, both ostia and cornua visualized, normal, anterior uterine wall surface normal. There was a polypoidal mass arising from the posterior wall, right laterally 3-4 cms. in size? placental polyp. The polyp was removed with an ovum forceps in toto and sent for histopathology. Scope was reintroduced to verify if removal was complete. Histopathology reported retained placental tissue. The patient improved thereafter, without any bleeding after the procedure.

\section{Case 2}

A primigravida was delivered by a lower segment caesarean section on $30^{\text {th }}$ June 2006 in a private hospital. Three weeks after the abdominal delivery, she had secondary PPH, two units of blood was transfused and referred to the Institute on $1^{\text {st }}$ August 2006. Severe pallor was noted at admission, uterus was 10 weeks in size, no excessive vaginal bleeding. After transfusing blood products and investigations, hysteroscopy was performed on $11^{\text {th }}$ August 2006, an irregular polypoidal tissue found along the posterior uterine wall and cervical canal was removed in toto, a gentle curettage was done. Histopathology of the tissue reported proliferative endometrium. Follow up USG, trans vaginal on $28^{\text {th }}$ August 2006, revealed no retained products of conception, (RPOC), scar normal and beta HCG was normal.

\section{Case 3}

This case also was managed in August 2006. This patient, para 2, live children 2, with two caesarean deliveries, developed secondary postpartum haemorrhage one week after the second Caesar. She was managed at the private hospital, a curettage was attempted and she started to bleed profusely, immediately was sent to the Institute with a note and also information about the referral through a telephonic conversation with the duty doctor at the Institute. After stabilizing her, and the necessary investigations, hysteroscopy revealed polypoidal tissue adherent to the anterior uterine wall above the site of the scar. Removal of the tissue was done with an ovum forceps and a gentle curettage was performed with the blunt curette. Bleeding stopped after the procedure. Histopathological examination confirmed retained placental tissue.

\section{Case 4}

Retained placenta due to submucous intracavitary fibroids. Role of hysteroscopy.

A nineteen years woman, Para o, abortion-1, referred from Owaisi hospital/Deccan Medical College, Hyderabad, with retained placenta after abortion. A case of multiple uterine fibroids (8-10 in number) aborted at 20 weeks gestation and was referred with retained placenta on $23^{\text {rd }}$ August 2006. At admission the patient was stable, uterine height was 34 weeks, no active bleeding per vaginum. Ultrasonography on $23^{\text {rd }}$ August 2006 revealed multiple intramural fibroids in the entire uterus. $88 \times 63 \mathrm{~mm}$ placental tissue in left lateral and anterior wall with rim of myometrium around it. Placental extraction was attempted under anaesthesia. With multiple fibroids obstructing the uterine cavity, ovum forceps could not be passed up to the fundus; placenta could not be removed in toto. On $24^{\text {th }}$ August 2006 Inj. Methotrexate was given. Repeat scan on $2^{\text {nd }}$ September 2006, showed the same placental mass at fundus. Hysteroscopy was done. Multiple uterine fibroids, submucous and intramural distorting the uterine cavity were visualised. Large polypoidal placental mass was noted at the fundus. The mass was removed with a sponge holding forceps. Histopathology revealed retained placenta. Repeat scan showed evidence of retained products of conception, (RPOC). Patient was sent home, she was having on and off spotting with monthly cycles, but no heavy bleeding. A second hysteroscopy was performed on $2^{\text {nd }}$ January 2007. Small placental tissue was seen at the fundus, which was evacuated completely. Patient was asymptomatic thereafter, underwent myomectomy in March 2007.

\section{Case 5}

A twenty-five years lady was admitted with the complaint of continuous bleeding per vaginum since 15 days. This woman had a caesarean section done in a nursing home, one month prior to admission to study hospital. She was para 2, live children 2, two previous caesareans with secondary postpartum haemorrhage of 15 days duration. A curettage was performed once to arrest the bleeding prior to referral. Since she continued to bleed, in spite of the curettage, was sent to study tertiary centre. Ultrasonography done at study Institute revealed echogenic lesion in the uterine cavity, hysteroscopic guided removal of the protuberant mass was done with complete relief to the lady. In this case the polypoidal tissue was just $8 \times 8 \mathrm{~mm}$, close to the lower segment scar area that was responsible for such heavy bleeding.

Hysteroscopy done during the puerperal period, in cases of secondary $\mathrm{PPH}$, had certain challenges to cope with. When PPH occurred one or two weeks postpartum, the length of the uterus was greater. Especially in the case with sub mucous fibromyomata, needed some expertise to pass the scope to a greater length.

\section{DISCUSSION}

Study had a crop of five cases of secondary postpartum haemorrhage, referral cases, during a period of six months during 2006. Four cases were following a caesarean delivery and in one, submucous and intra mural, multiple uterine fibroids, caused retained placental tissue by distortion of the uterine cavity and secondary $\mathrm{PPH}$. Hysteroscopic guided excision of the placental 
tissue was one-time treatment in four of study cases, and one needed a second hysteroscopic excision. Secondary PPH occurred at varying periods after the caesarean delivery, one week in one, two weeks in one case, three weeks in two cases and one woman was admitted with retained placenta, primary $\mathrm{PPH}$ continuing to secondary $\mathrm{PPH}$.

Hatfield JL, Cooper BC et al, reported two cases of nulliparous women who had following spontaneous vaginal delivery, manual placental extraction and delayed postpartum haemorrhage. ${ }^{9}$ Suction curettage with ultrasound guidance could not control the secondary PPH. They subsequently underwent hysteroscopic resection of the persistent products of conception, detected on imaging, with complete resolution of symptoms. Hatfield et al conclude that hysteroscopic resection is a conservative therapeutic option for placenta accreta in stable patients. ${ }^{9}$

Twelve consecutive patients with hysteroscopic resection of retained tissues after conservative management of placenta accreta were reported by Legendre GI et al. ${ }^{10}$ Complete evacuation of the uterus was completed after 1 procedure in 5 patients, after 2 procedures in 2 patients, and after 3 procedures in 4 patients. Complete removal was achieved in all but 1 patient who underwent a secondary hysterectomy. ${ }^{10}$ Hysteroscopic resection of retained placenta seems to be a safe and effective procedure to prevent major complications and to preserve fertility in cases of conservative management of placenta accreta. $^{10}$

Retained placental products are the commonest cause of secondary PPH. Surgical evacuation \pm , curettage, was done in $85 / 132$ cases, $64 \%$ had surgical evacuation, 39 without USG, 46 after a scan report. ${ }^{3}$

Retained products of conception (RPOCs) was the leading cause in $36(72 \%)$ of patients, curettage was done in $40(80 \%)$ of patients including 36 having RPOCs and check curettage in four patients. ${ }^{11}$ RPOCs was documented as the most common cause of secondary PPH. ${ }^{12,13}$

Among 33 cases of secondary PPH, most common causes found were, retained bits of placenta in 11 (34\%) patients, $27 \%$ uterine wound dehiscence, $24 \%$ retained clots and $15 \%$ endometritis. ${ }^{14}$ Manual vacuum aspiration (MVA) was done in $18(55 \%)$ patients, laparotomy followed by repair of uterine wound was done in $4(12 \%)$ patients. They have used MVA for retained products of conception and retained clots. ${ }^{14}$

The traditional causes of postpartum hemorrhage, which typically are retained placental fragments, are less likely to arise after $\mathrm{C}$. section, because the delivery of the placenta is directly observed. ${ }^{15,16}$ Eight patients $(0.15 \%)$ who had delivered by caesarean section, developed secondary PPH, while six $(0.26 \%)$ of patients who delivered vaginally developed secondary $\mathrm{PPH} .{ }^{11}$

In this study, four of the five cases of secondary PPH were following caesarean delivery. Retained products are not uncommon after caesarean because various factors could be operative, like localized adherent placental products, deep cornua of the uterus as an anatomical variation, previous scars on the uterus where the membranes may not easily peel off during placental removal and most importantly, in a caesarean delivery, it is not a physiologic separation and placental expulsion as in vaginal delivery, it is more like placental removal with hand, hence chances of incomplete removal is possible.

Greenberg JA et al, report a patient who was diagnosed with a retained placenta accreta and underwent successful conservative treatment with uterine artery embolization followed by hysteroscopic morcellation. Whereas other methods have failed due to bleeding and/or infection, this case illustrates a potential new means of addressing this challenging obstetrical complication. ${ }^{17}$

Khan $\mathrm{M}$ et al, have reported a case of placenta percreta managed conservatively using uterine artery embolization followed by injection methotrexate. ${ }^{18}$ Selective arterial embolization in management of secondary postpartum hemorrhage due to spontaneous rupture of the uterine artery following a normal vaginal delivery has been reported. ${ }^{19}$

Pather S et al, have reported significant complications in three cases of placenta percreta managed conservatively. ${ }^{20}$ Retaining the placenta in situ at caesarean section for placenta percreta and awaiting placental reabsorption was widely practiced in the past. But $40 \%$ of women subsequently require surgery, emergency hysterectomy and $42 \%$ will experience major morbidity. ${ }^{20}$

Meyer NP et al, reported 12 patients who underwent caesarean section, placenta percretae were intentionally left in situ, emergency hysterectomy for massive obstetric haemorrhage in one, disseminated intravascular coagulation in one, early sepsis in one, delayed sepsis in three, re-embolization to control persistent haemorrhage in one, have been reported. ${ }^{21}$ They have reported an average blood loss of $2490 \mathrm{ml}$ and $1425 \mathrm{ml}$ was the mean volume transfused in the cases. ${ }^{21}$

Karmous $\mathrm{N}$ et al, described two cases of late post-partum hemorrhage from uterine artery pseudoaneurysm, (UAP) diagnosed as such using color doppler US, UAP illustrates a rare vascular complication after caesarean section. ${ }^{6}$ UAP has been reported after hysterectomy and myomectomy also. Ligation of the uterine artery during the surgical procedures can lead to aneurysmal dilatation and formation of pseudoaneurysms. It is important to recognize this uterine vascular abnormality as a surgical complication. If retained placental products are not 
identified, after a routine scan of the uterus, by using color doppler US, should look for UAP, in cases of secondary PPH after a caesarean delivery.

Since retained placental products have been mentioned as the most common cause of secondary PPH, it becomes necessary to do an ultrasound scan to detect retained placental products (RPP). Where facilities are unavailable, for hysteroscopy, evacuation with an ovum forceps, or a dilatation and gentle curettage or manual vacuum aspiration (MVA), are the procedures followed. In case the bleeding continues, the blind procedures may not have completely removed the placental products, in some instances, adherent placenta in certain areas, could well be managed by hysteroscopy. Hysteroscopic guided procedures are less invasive, and do not need a wellequipped radiology department which is needed for uterine artery embolization, less invasive compared to pelvic vessel ligation and hysterectomy. Certain operations like B Lynch are mainly meant for atonic $\mathrm{PPH}$.

In the final analysis of various procedures to control PPH, hysteroscopic excision and removal of the placental products scores over other surgical methods as a specific targeted intervention. Study need to train a greater number of obstetric and gynaec specialists to consider this procedure when the need arises.

\section{CONCLUSION}

Hysteroscopic guided resection of the retained placental tissue was successful in all the five cases with secondary postpartum haemorrhage, after confirmation by transvaginal sonography. Precise identification of the causative factor of PPH and targeted treatment is facilitated by hysteroscopy. Professionals skilled in hysteroscopic procedures should be available in tertiary care centres, so that conservative uterine procedures can be performed with reduction in maternal morbidity and mortality. With the use of hysteroscopy, the other procedures of leaving the placenta in situ, suction curettage, use of methotrexate injection and uterine artery embolization can be avoided in future times. Hysteroscopy is an excellent procedure in cases of secondary PPH. Study request guidelines committees to consider including hysteroscopic guided removal of retained placental products, in the algorithm of management of secondary PPH.

\section{Funding: No funding sources}

Conflict of interest: None declared

Ethical approval: The study was approved by the Institutional Ethics Committee

\section{REFERENCES}

1. Alexander J, Thomas PW, Sanghera J. Treatments for secondary postpartum haemorrhage. Cochrane Database Syst Rev. 2002;1:CD002867.
2. Aiken CEM, Mehasseb M, Prentice A. Secondary postpartum haemorrhage. Fetal Mater Med Rev. 2012;23(1):1-14.

3. Hoveyda F, MacKenzie IZ. Secondary postpartum haemorrhage: incidence, morbidity and current management. BJOG. 2001;108(9):927-30.

4. King PA, Duthie SJ, Dong ZG, Ma HK. Secondary postpartum haemorrhage. Aust N Z J Obstet Gynaecol. 1989;29:394-8.

5. Zubor P, Kajo K, Dokus K, Krivus S, Straka L, Bodova KB, Danko J. Recurrent secondary postpartum hemorrhages due to placental site vessel subinvolution and local uterine tissue coagulopathy. BMC Preg Childbirth. 2014;14(1):80.

6. Karmous N, Karmous N, Ayachi A, Derouich S, Mkaouar L, Mourali M. Rupture of uterine artery pseudoaneurysm: role of ultrasonography in postpartum hemorrhage management. Pan African Med J. 2016;25:136.

7. Dhar RS, Misra R. Postpartum uterine wound dehiscence leading to secondary PPH: unusual sequelae. Case Rep Obstet Gynecol. 2012;154:685.

8. Baba T, Morishita M, Nagata M, Yamakawa Y, Mizunuma M. Delayed postpartum hemorrhage due to cesarean scar dehiscence. Arch Gynecol Obstet. 2005;272(1):82-3.

9. Cooper BC, Hatfield JL. Brumsted JR. Conservative treatment of placenta accreta. J Minim Invasive Gynecol. 2006;13(6):510-3.

10. Legendre G, Zoulovits FJ, Kinn J, Senthiles L, Fernandez H. Conservative management of placenta accreta: hysteroscopic resection of retained tissues. Minim Invasive Gynaecol. 2014;21(5):910-3.

11. Nigeen W, Mariya F, Asima A, Sameena A, Abdus SB. Secondary postpartum haemorrhage in a tertiary care hospital of North India: a retrospective analysis. Int J Reprod Contracept Obstet Gynecol. 2017;6(2):532-6.

12. Ajenifuja KO, Adepiti CA, Ogunniyi SO. Postpartum haemorrhage in a teaching hospital in Nigeria: a 5-year experience. African Health Sci. 2010;10(1):71-4.

13. Dossou M, Debost-Legrand A, Déchelotte P Lémery D, Vendittelli F. Severe secondary postpartum hemorrhage: a historical cohort. Birth. 2015;42(2):149-55.

14. Nessa K, Bari S, Khan S, Sultana F, Akbar T. Causes and management of secondary postpartum haemorrhage in a tertiary medical college hospital in Bangladesh. Int $\mathbf{J}$ Reprod Contracept Obstet Gynecol. 2017;6:2694-7.

15. Keane B. Recurrent secondary postpartum haemorrhage after lower segment caesarean section. N Z Med J. 1973;78:256-7.

16. Ross JE, Galliford BW. Late hemorrhage following cesarean section. Am J Obstet Gynecol. 1974;119:858-9.

17. Greenberg JA, Miner JD, O'Horo SK. Uterine artery embolization and hysteroscopic resection to treat 
retained placenta accreta: a case report. J Minim Invasive Gynaecol 2006;13(4):342-4.

18. Khan M, Sachdeva P, Arora R, Bhasin S. Conservative management of morbidly adherent placenta - a case report and review of literature. Placenta. 2013;34(10):963-6.

19. Thakur M, Adekola HO, Asaad R, Gonik B. Secondary postpartum hemorrhage due to spontaneous uterine artery rupture after normal vaginal delivery managed by selective arterial embolization. Am J Perinatol Rep. 2016;6:e442e444.

20. Pather S, Strockyi S, Richards A, Campbell N, de Vries B, Ogle R. Maternal outcome after conservative management of placenta percreta at caesarean section: a report of three cases and a review of the literature. Aust N Z J Obstet Gynaecol. 2014;54(1):84-7.

21. Meyer NP, Ward GH, Chandraharan E. Conservative approach to the management of morbidly adherent placenta. Ceylon Med J. 2012;57(1):36-9.

Cite this article as: Devabhaktuni $\mathrm{P}$, Allani $\mathrm{P}$. Hysteroscopy to identify retained placental tissue and excision in secondary post-partum haemorrhage. Int J Reprod Contracept Obstet Gynecol 2020;9:1847-52. 